\title{
Enhanced Functionality of Maillard-reaction Products Derived from Milk Protein through Lactic Acid Bacteria Fermentation
}

\author{
Nam Su Oh${ }^{1}$, Yong Kook Shin ${ }^{1}$, Younghoon Kim², Kwang Won Lee ${ }^{3}$, and Sae Hun Kim ${ }^{3 *}$ \\ ${ }^{I} R \& D$ Center, Seoul Dairy Cooperative, Ansan 425-839, Korea \\ ${ }^{2}$ BK21 Plus Graduate Program, Department of Animal Science, Chonbuk National University, Jeonju 561-756, Korea \\ ${ }^{3}$ Division of Food Bioscience and Technology, College of Life Science \& Biotechnology, \\ Korea University, Seoul 136-713, Korea
}

\begin{abstract}
The Maillard reaction is a complex reaction that occurs between carbonyl and amine groups during food processing and storage. In addition, it produces a large number of Maillard reaction products (MRPs), which have an important role in determining food characteristics including aroma, color, flavor, and texture. Importantly, recent studies have been conducted that the Maillard reaction products and their ferments with lactic acid bacteria (LAB) induced specific biological characteristics including antimicrobial, antioxidative, and antihypertensive activities as well as improved their physiological features such as the heat stability and emulsifying properties. Therefore, we described on new insights for enhanced physiologic and biologic functions of MRPs through LAB fermentation.
\end{abstract}

Keywords: Maillard reaction products, Lactic acid bacteria, fermentation

\section{Introduction}

The Maillard reaction is a complex reaction that occurs between carbonyl and amine groups during food processing and storage. It produces a large number of Maillard reaction products (MRPs), which play an important role in determining food characteristics including aroma, color, flavor, and texture (Fayle and Gerrard, 2002). At an early stage of the reaction, proteins containing free amino groups react with carbonyl groups of sugars to form a reversible Schiff bases, which give rise to stable 'Amadori compounds' through rearrangement. In the advanced stage of the reaction, Amadori compounds lead to the formation of colored and fluorescent substances (Jing and Kitts, 2002).

Milk protein is known to contain valuable components and biologically active substances (Chevalier et al., 2001) and has been widely used as a functional ingredient in food applications. The bioactive peptides derived from milk proteins may function with antioxidant, immune-

\footnotetext{
*Corresponding author: Sae Hun Kim, Division of Food Bioscience and Technology, College of Life Science \& Biotechnology, Korea University, Seoul 136-713, Korea

Tel: 82-2-3290-3055, Fax: 82-2-3290-3506

E-mail: saehkim@korea.ac.kr

Received June 16, 2015; Revised June 20, 2015;

Accepted June 23, 2015
}

modulating, antithrombotic, antihypertensive, and antibacterial properties (Gobbetti et al., 2000; Meisel, 1997; Smacchi and Gobbetti, 2000). In particular, Maillard reaction products (MRPs), which are produced by reactions between carbonyl and amine groups, not only produce food characteristics such as aroma, color, flavor, and texture (Fayle, 2002), but also increase the antioxidant activity of milk proteins (Chevalier et al., 2001; McGookin and Augustin, 1991). Several studies have been conducted that the Maillard reaction improved the heat stability, emulsifying properties, and antioxidant activity of whey protein (Chevalier et al., 2001); hence, these results propose that physiologic and biologic functions of milk protein could be improved by the Maillard reaction. Also, in recent years, Maillard reaction products derived from milk proteins have studied for their biological activities; antimicrobial, anti-oxidative, antihypertensive, and antibrowning activities (Kwon et al., 2006; Rufián-Henares and Morales, 2007).

\section{Milk protein and Maillard reaction products (MRPs)}

\section{Milk protein}

Milk is a white liquid produced by the mammary glands of mammals. It is the primary source of nutrition for young mammals until they are able to digest other 
types of foods. Milk is an important food with many nutrients (Pehrsson et al., 2000). Milk contains nutrients which required for the growth and development of the neonate. All milks contain specific proteins and fats which designed to make digest easier, and also the milks contains lactose, minerals, vitamins, and other components which taking an important roles (Jensen et al., 1991).

Milk protein is known to contain valuable components and biologically active substances (Chevalier et al., 2001), and has been widely used as a functional ingredient in food applications. Milk proteins can be classified by 2 major groups: casein and whey protein (the ratio of 80 : 20) (Fox and McSweeney, 2003). After processing occurs, the caseins are the proteins responsible for making curd, while whey proteins remain in an aqueous environment (Marshall, 2004). The casein proteins are phosphoproteins and divide themselves into two groups. $K$-casein is calcium-insensitive and $\alpha_{\mathrm{S} 1-}, \alpha_{\mathrm{S} 2-}$ and $\beta$-casein are the three calcium-sensitive members (Horne, 2006), and these sub species form a casein micelle in milk. The components of whey include $\beta$-lactoglobulin, $\alpha$-lactalbumin, bovine serum albumin (BSA), lactoferrin, immunoglubulins, lactoperoxidas, and glycomacropeptides, etc (Marshall, 2004).

\section{Maillard Reaction products (MRPs)}

The Maillard reaction, a chemical reaction between amino groups and reducing sugars, is very significant for foods because it strongly affects food quality (Van Boekel, 1998). Maillard reaction products (MRPs), which are naturally produced in food during heat processing by reducing the sugars that interact with available amino acids (Hwang et al., 2011). In the case of milk, amino groups are mainly lysine residues in milk proteins (Walstra and
Jenness, 1984). Lysine residues in caseins seem to be more reactive than in serum proteins, while $\mathrm{K}$-casein seems to be the most reactive casein (Turner et al., 1978). The reducing sugar in milk is lactose, a disaccharide of glucose and galactose and the monosaccharides (i.e. glucose and galactose) are found in raw milk only in very low concentrations (Van Boekel, 1998).

The Maillard reaction is sometimes subdivided into three stages: the early Maillard reaction, the advanced Maillard reaction and the final Maillard reaction (Mauron, 1981). The early Maillard reaction consists of condensation of the reducing sugar with the amino group and leads, via formation of a Schiffs base and the Amadori rearrangement, to the so-called Amadori product (Fig. 1). In milk, this Amadori product is lactulosyllysine (bound to protein). The advanced Maillard reaction consists of the breakdown of the Amadori product (or other products related to the Schiffs base) into numerous fission products of the sugar-amino compound. The final Maillard reaction consists of the condensation of amino compounds and sugar fragments into polymerized protein and brown pigments, called the melanoidins, the chemical nature of which is still rather obscure (Van Boekel, 1998).

\section{Biological activities of MRPs}

In the previous studies, Maillard reaction have only focused on the reactants, color development or the formation of intermediate MRPs and other products, but its biological functionality has not been conducted. In recent years, several studies have focused on the effect of MRPs on antimicrobial, anti-oxidative, antihypertensive, and anti-browning activities (Kwon et al., 2006; Rufián-Henares and Morales, 2007).

$\mathrm{Gu}$ (Gu et al., 2009) reported that heated casein-glu-
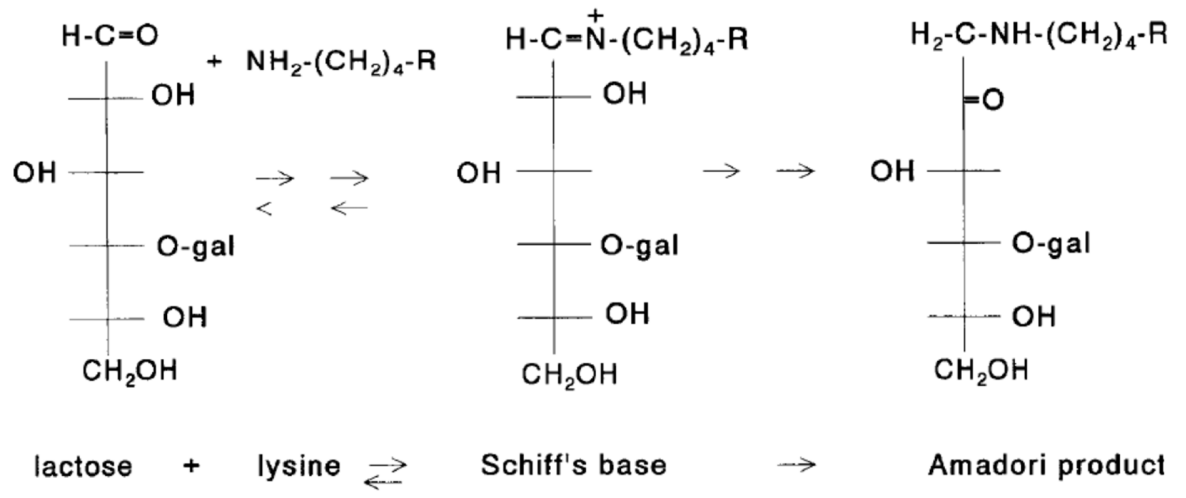

Schiff's base

Amadori product (lactulosyllysine-R)

Fig. 1. Schematic overview of the early Maillard reaction in milk, leading to the Amadori product. $($ gal $=$ galactose, $\mathrm{R}=$ protein chain) (adapted from Van Boekel, 1998). 
cose mixtures decreased rates of lipid peroxidation in an emulsified linoleic acid model. In addition, caseinatesugar-derived MRPs exhibited antioxidant activity against Fenton reactant-induced hydroxyl free radicals, but not against hydrophobic radicals (Gu et al., 2009). In accordance with Kwon (Kwon et al, 2006), total polyphenol, flavonoid, and 5-HMF contents increased with increasing treated temperature and time due to non-enzymatic Maillard reaction during the garlic juice heating process and these resulted increased antioxidant activities. In addition, melanoidins formed at the last stage of the Maillard reaction have been pointed out to possess certain functional properties. It possess antioxidant (Delgado-Andrade and Morales, 2005; Delgado-Andrade et al., 2005; Manzocco et al., 2000; Morales, 2005), antimicrobial (Del Castillo et al., 2007; Ruán-Henares and Morales, 2007) and prebiotic activities (Borrelli \& Fogliano, 2005).

\section{Hydrolysis of milk proteins and MRPs}

Biologically active peptides are food-derived peptides that exert a physiological, hormone-like effect in humans as well as their nutritional value. They are inactive within the sequence of their parent protein and can be released by enzymatic hydrolysis either during gastrointestinal digestion or during food processing (e.g., cheese ripening and milk fermentation). They usually contain 2-20 amino acid residues per molecule, but in some cases may consist of more than 20 amino acids. Milk protein hydrolysate via enzymatic proteolysis or probiotic fermentation can either be absorbed through the intestine to enter the blood circulation intact and exert systemic effects, or produce local effects in the gastrointestinal tract. Depending on the sequence of amino acids, these peptides can exhibit diverse activities, including opiate-like, mineral binding, immunomodulatory, antimicrobial, antioxidant, antithrombotic, hypocholesterolemic, and antihypertensive actions, in addition to aiding in the mineral absorption of calcium (Hartmann and Meisel, 2007; Kitts and Weiler, 2003; Kovacs-Nolan et al., 2005; LeBlanc et al., 2002; Meisel, 1997). Many of the known bioactive peptides are multifunctional and can exert more than one of the effects mentioned (Korhonen and Pihlanto, 2003; Meisel, 2004; Meisel and FitsGerald, 2003). Because of their healthenhancing potential and safety profiles they may be used as components in functional foods or nutraceuticals. However, milk proteins are currently the main source of several biofunctional peptides and daily intake of milk and milk products has proved to be physiologically important to both neonates and adults (Appel et al., 1997;
Pfeuffer and Schrezenmeir, 2000; Severin and Wenshui, 2005). Antimicrobial peptides have been derived from the minor whey protein, lactoferrin. The peptide degraded from lactoferrin has bactericidal property more potent than undigested lactoferrin, suggesting its much smaller size may facilitate access to target sites on the microbial surface (Tomita et al., 1994). Antihypertensive effect is related with inhibition of the angiotensin converting Enzyme (ACE). The casein-derived ACE inhibitors, or casokinins, represent different fragments of human and bovine casein. For example, highly active casokinins represent 14 and 15 , which are present in the bovine $\beta$-casein and $\alpha_{\mathrm{S}_{1}}$-casein sequence, respectively (Meisel, 1999). In addition, the bioactivity of immune-peptides from milk protein was characterized by different in vitro and in vivo test systems in several studies with casein-derived peptides including the ACE inhibitory fragment 17 of $\alpha_{\mathrm{S}^{-}}{ }^{-}$ casein and 19 and 20 of $\beta$-casein, and they have been shown to stimulate phagocytosis of sheep red blood cells by murine peritoneal macrophages, and to exert a protective effect against bacterial infection in mice (MiglioreSamour, 1989). Moreover, it has been reported that phosphopeptides from milk proteins can form soluble organophosphate salts and may function as carriers for different minerals, especially calcium (Sato et al., 1986). The mode of action for mineral absorption is correlation with negatively charged side chains, in particular the phosphate groups, of amino acids to represent the binding sites for minerals. Other studies have shown that a proteinase from L. helveticus CP790 was able to release an antihypertensive peptide from casein hydrolysates (Maeno et al, 1996; Yamamoto et al., 1994).

Although enzymatic and microbial hydrolysis of milk protein has been conducted well, in particular various cardiovascular protective effects of milk derived peptides (Table 1), hydrolysis of MRPs has not been studied well. Amadori compounds, one of the intermediate of Maillard reaction products, could be partially hydrolyzed by proteinase because of its protein backbone structure. In this study, we could expect the production of biological peptides from enzymatic proteolysis and probiotic fermentation of MRPs.

Lactic acid bacteria (LAB) fermentation of milk proteins and MRPs

Only a few studies exist on the potential protective cardiovascular effects (reduction of cholesterol uptake, inhibition of thrombin and HMGR, fibrinolytic activity) of milk-derived compounds fermented by lactic acid bacte- 
Table 1. The list of peptides with preventive effect on cardiovascular health derived from milk proteins

\begin{tabular}{ccc}
\hline Activity & Origin & Sequence/name \\
\hline Antioxidant & Casein & YFYPEL \\
& $\beta$-lactoglobulin & K-casein \\
Antithrombotic & lactoferrin & MHIRL, YVEEL, WYSLAMAASDI \\
Hypocholesterolmic & $\beta$-lactoglobulin & MAIPPKKNQDK (casoplatelin) and smaller fragments \\
Hypotensive & casein & KRDS \\
Antiobese & K-casein & IIAEK (lactostatin) \\
& & FFVAPFPEVFGK \\
\end{tabular}

ria (LAB). Therefore, our group was investigating that the enhanced functionality of MRPs via fermentation on the preventive cardiovascular effects.

In recent, we reported that the hydrolysates of MRP with fermentation by selected strains of lactic acid bacteria (LAB) including Lactobacillus gasseri and L. fermentum significantly induced the anti-oxidant activity in 1,1diphenyl-2-picrylhydrazyl (DPPH) radical scavenging assays, ferric-reducing power assay, and 2,2'-azino-bis (3ethylbenzothiazoline-6-sulfonic acid) diammonium salt (ABTS) radical scavenging assay (Oh et al., 2014). In addition, the specific biological properties were enhanced by LAB fermentation. MRPs fermented by $L$. gasseri demonstrated the greatest activity for thrombin and 3hydroxy-3-methylglutaryl-CoA reductase (HMGR) inhibition (Oh et al., 2014). Equally importantly, we indicated that MRPs fermented by LAB positively influenced on cardiovascular health in ICR mouse and rat models (Oh et al., 2015). Taken together, the heath-promoting effect of MRP was synergistically improved by LAB fermentation. To date, we are evaluating on the identification and characteristics of small unknown compounds that were likely released by fermentation of MRP by size-exclusion chromatography and Matrix-assisted laser desorption/ionization time-of-flight/mass spectrometry (MALDI-TOF/ MS).

\section{Antioxidant Activity and Cardiovascular Health}

\section{Antioxidant activity}

All organisms are exposed to reactive oxygen species (ROS) or reactive oxygen metabolites (ROM), such as hydrogen peroxide $\left(\mathrm{H}_{2} \mathrm{O} 2\right)$, superoxide anions $\left(\mathrm{O}_{2}{ }^{2 \cdot}\right)$ or hydroxyl radicals $\left(\mathrm{OH}_{2}\right)$, as a byproduct of oxidative metabolism or through exposure to radical-generating compounds (Yu, 1994). Free radicals and ROS are closely associated with various degenerative diseases including atherosclerosis, ischemic heart disease, and aging, etc. (Belch et al., 1991; Comporti, 1985; Halliwell and Gutteridge, 1990; Steinbrecher et al., 1990). Superoxide ani- ons are readily generated through the one-electron reduction of oxygen by transition metal ions and then dismutated into hydrogen peroxide by enzymatic and nonenzymatic mechanisms (Fridovich, 1989). Hydrogen peroxide is then further converted into hydroxyl radicals $(\mathrm{OH} \cdot)$, which are highly reactive as the initiating species for cellular and plasma lipid peroxidation (Aust and Svingen, 1982; Fridovich, 1989). They promptly react with cellular macromolecules such as lipids, proteins, and nucleic acids eventually leading to cell death. Superoxide dismutase (SOD), catalase (CAT), and glutathion peroxidase (GSH$\mathrm{Px})$ are the primary intracellular antioxidant enzymes which cooperate on the detoxification of the free radicals produced during normal aerobic respiration. $\mathrm{Cu}, \mathrm{Zn}$-SOD resolves $\mathrm{O}_{2}^{2}$. into $\mathrm{H}_{2} \mathrm{O}_{2}$ and $\mathrm{O}_{2}$, whereas CAT and GSHPx catalyze the reduction of $\mathrm{H}_{2} \mathrm{O}_{2}$ to $\mathrm{H}_{2} \mathrm{O}$.

Under oxidant stress, the increased production of reactive oxygen species (ROS) in combination with outstripping endogenous antioxidant defense mechanisms, is another significant causative factor for several cardiovascular diseases. ROS can cause extensive damage to biological macromolecules like DNA, proteins and lipids (Ames et al., 1993). Specifically, oxidative modifications of LDL occur, leading to atherosclerosis. Free radicals generated from reduction of oxygen may cause cellular damage and contribute to atherosclerosis, arthritis, diabetes, and carcinoma (Aviram, 2000; Halliwell, 1994). The major effect of antioxidants is to prevent the formation of oxidized LDL and severe tissue injury. Meanwhile, antioxidant activities prevent enzymatic (lipoxygenase-mediated) and nonenzymatic peroxidation of lipids and essential fatty acids (Chen et al., 1996), however the exact mechanisms behind these effects are not fully understood. Possible mode of action may be the induction of genes which protect cells from damage by ROS. Rival (Rival et al., 2001) reported that caseins and casein-derived peptides were found to inhibit lipoxygenase, an enzyme which catalyzes the peroxidation of unsaturated fatty acids such as linoleic acid. Moreover, emerging evidence suggests that increased oxidative stress is a mechanism of endothelial dys- 
function in hypercholesterolemia (Keaney et al., 1993; Ohara et al., 1993). Improved endothelial vasomotor function raised the possibility that the addition of an antioxidant drug increases the beneficial effect of lipid lowering therapy on endothelial function. In addition to the well-known dietary antioxidants like vitamin $\mathrm{C}$, vitamin E, polyphenols and carotenoids, other dietary compounds have generated particular interest as defenses against oxidative damage. Recent studies have shown that peptides with antioxidant properties can be released from food sources such as milk casein (Suetsuna et al., 2000), whey protein (Hemandez-Ledesma et al., 2005), egg (Davalos et al., 2004; Ishikawa et al., 2004) and soy protein (Chen et al., 1995). The antioxidant activity of whey-derived peptides and whey itself has been linked with the presence of cysteine-rich proteins which promote the synthesis of glutathione, a potent intracellular antioxidant (Meisel, 2005). In a study by Rival et al. (2001), caseins and casein-derived peptides were found to inhibit lipoxygenase, an enzyme which catalyzes the peroxidation of unsaturated fatty acids such as linoleic acid.

\section{Antithrombotic activity}

In Cardiovascular diseases, thrombin acts as a major pathogenic factor. Generally thrombin is a multifunctional protease generated at sites of vascular injury, and trigger fibrin formation, platelet aggregation, and chemotatic for monocytes, mitogenic reaction for lymphocytes, fibro- blast, and vascular smooth muscle cells (Coughlin, 1994). Thrombus defined as a localized clotting of the blood, and consists of fibrin clot, aggregated platelet, various blood cells and immune cells. Increased occurrence of thrombosis has been linked to platelet hyperreactivity, high levels of hemostatic proteins (e.g., fibrinogen), defective fibrinolysis and hyperviscosity of the blood (Bertina, 1999). Hence, antithrombotic drugs are commonly used to reduce platelet aggregation and enhance fibrinolysis. The coagulation cascade, which is platelet aggregation, is the sequential process by which coagulation factors of the blood interact and are activated, ultimately generating fibrin, the main protein component of the thrombus, and this cascade operates in both arterial and venous thrombosis (Mackman, 2008). Generally, these processes are initiated by the damage of endothelial cells of the vessel wall, go through the "intrinsic" or "extrinsic" pathway, and end up with the "common pathway" and these pathways were described in Fig. 2. The main target of anticoagulation drugs is thrombin inhibitor. Thrombin inhibitor could act on anti-platelet and inhibition of fibrinogen degradation. Thrombin inhibitor can block the action of thrombin by binding to three domains: the active site or catalytic site and catalyze the inactivation of thrombin and activated factor X (factor Xa) by antithrombin (Weitz and Crowther, 2002). The main antithrombotic peptide MAIP PKKNQDK, isolated from the soluble C-terminal fragment (caseinoglycomacropeptide) of bovine K-casein, cor-

\section{Contact activation (intrinsic) pathway \\ Tissue factor (extrinsic) pathway}

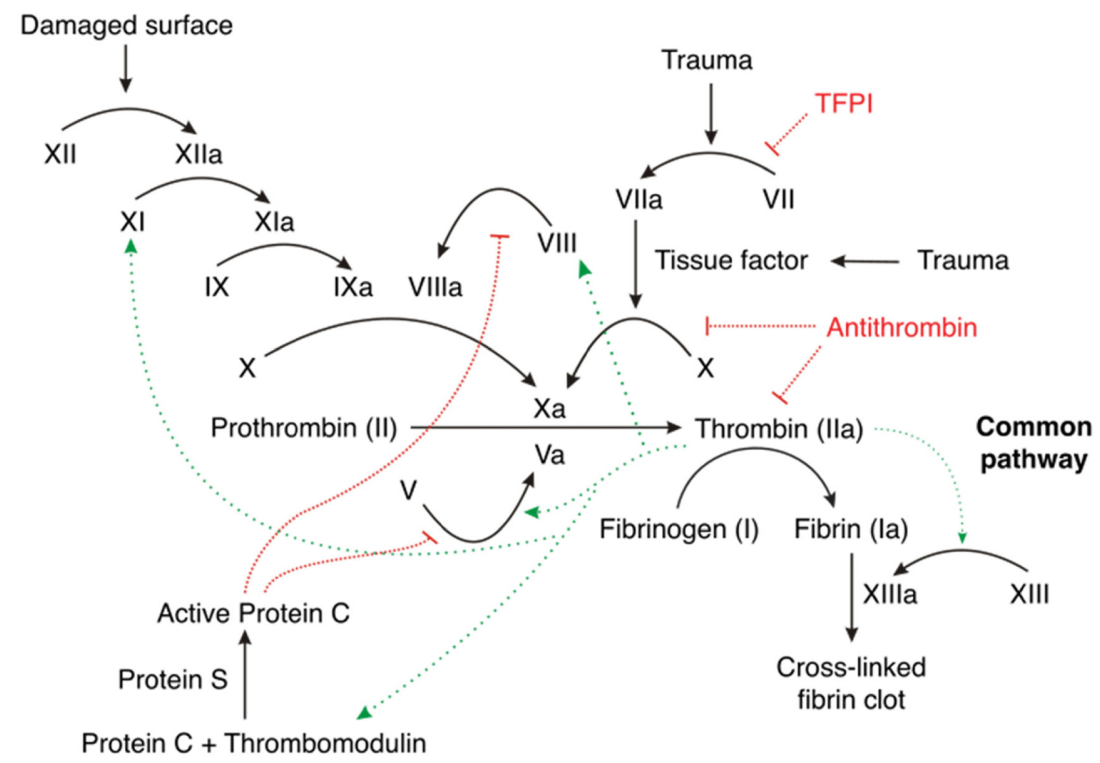

Fig. 2. The pathways of blood coagulation cascade (adapted from Mosesson, 1998). 
responds to the residues 106 to 116 of $\kappa$-casein and is termed casoplatelin. This undecapeptide inhibits both the aggregation of ADP activated platelets as well as the binding of human fibrinogen $\gamma$-chain to its receptor region on the platelet surface (Jolles et al., 1986). Three amino acid residues (Ile108, Lys112, Asp115) of the aforementioned undecapeptide seem to be important for the antithrombotic effect, because they are homologous in positions to the $\gamma$-chain sequence of human fibrinogen. Therefore, antithrombotic activity is influenced by the competition for platelet receptors between casoplatelin and the $\gamma$ chain of human fibrinogen. Furthermore, a correlation between sugar level and antithrombotic activity has been suggested since the human $\mathrm{K}$-caseinoglycomacropeptide, which is richer in sugars than that in bovine, is reportedly more potent (Chabance et al., 1995). In vivo antithrombotic activities have been shown for the $\mathrm{K}$-casein-derived undecapeptide (Maubois et al., 1991) as well as for the lactoferrin-derived tetrapeptide (Drouet et al., 1990). In addition, no detectable toxic effect has been reported. Hence, caseinoglycomacropeptide could potentially be used to treat or prevent thrombosis.

\section{Cholesterol lowering activity}

An unfavorable profile of blood lipids and serum cholesterol level are other important risk factors for the genesis of various CVD. Hypercholesterolemia (elevated serum cholesterol) leads over time to atherosclerosis and CVD. Serum cholesterol is produced both through hepatic cholesterol synthesis, the rate of which is controlled by 3-hydroxy-3-methylglutaryl-CoA reductase (HMGR), and through intestinal cholesterol uptake. Many studies have been performed in which the control of serum cholesterol levels via HMGR inhibition or suppression of cholesterol uptake through reduction of cholesterol solubility have been evaluated (Daniel et al., 2003; Duangjai et al., 2013; Ngamukote et al., 2011). It is generally known that proteins can improve blood lipid profiles. In recent study, hypocholesterolemic properties have been reported for soy, whey and fish protein, capable of altering the plasma profile from atherogenic to cardioprotective (Hori et al., 2001; Wergedahl et al., 2004; Zhang et al., 1993). The exact mechanisms responsible for the hypocholesterolemic effects have not been fully identified, but evidence suggests that the specific amino acid composition probably influences the effect of the protein source on plasma cholesterol levels. It has been reported that dietary proteins with low ratios of methionine-glycine and lysinearginine. When amino acid mixtures similar with soy pro- tein were fed to rats or rabbits, the resulting blood cholesterol levels were significantly lowered but not as low as those that were fed with the intact protein (Huff and Carroll, 1980; Nagata et al., 1982). It has also been shown that soy protein hydrolysates reduce total cholesterol levels more effectively than intact soy protein (Sugano et al., 1990; Wang et al., 1995). Several more reports indicated that hydrophobic peptides derived from soy protein bound bile acids thereby enhancing fecal steroid excretion which may contribute to the hypocholesterolemic activity (Iwami et al., 1986; Making et al., 1988). Numerous studies have shown that milk whey protein, in contrast to milk casein, decreases serum cholesterol similar to soy protein (Nagaoka, 1996; Nagaoka et al., 1991; Nagaoka et al., 1992). This effect was more marked with the whey peptide fraction than with the intact whey protein (Nagaoka, 1996). Following oral administration to rats, total serum cholesterol levels were significantly lower, whereas HDL concentration and atherogenic index (HDL cholesterol/ total cholesterol) were significantly higher than in the group fed with $\beta$-sitosterol. These effects have been speculated to be at least in part due to a decrease of micellar solubility of cholesterol which leads to lower intestinal cholesterol absorption (Nagaoka et al., 2001). Recent data have shown that lactostatin is capable of inducing the gene transcription of human cholesterol 7áhydroxylase (CYP7A1), a cholesterol-metabolizing enzyme, resulting in hypocholesterolemic effects. Moreover, both LPYRP and IAVPGEVA inhibited HMGR and it was revealed that the hydrophobic region (especially the maximum length of the hydrophobic sequence was four amino acids) of both peptides is a required structural element for their biological activity (Pak et al., 2005; Takenaka et al., 2000).

\section{References}

Ames BN, Shigenaga MK, and Hagen TM (1993) Oxidants, antioxidants, and the degenerative diseases of aging. Proc. Natl. Acad. Sci. USA 90, 7915-7922.

Appel LJ, Moore TJ, Obarzanek E, Vollmer WM, Svetkey LP, Sacks FM, and et al. (1997) A clinical trial of the effects of dietary patterns on blood pressure. DASH Collaborative Research Group. N. Engl. J. Med. 336, 1117-1124.

Aust SD and Svingen BA (1982) In Free Radicals in Biology (Pryor WA., Ed), Academic Press, New York. 1-28.

Aviram, M (2000) Review of human studies on oxidative damage and antioxidant protection related to cardiovascular diseases. Free Radic. Fes. 33(Suppl.), S85-S97.

Belch JJF, Bridges AB, Scott N, and Chopra M (1991) Oxygen free radicals and congestive heart failure. British Heart J. 65, 
245-248.

Bertina RM (1999) Molecular risk factors for thrombosis. Thromb Haemost. 82, 601-609.

Borrelli RC and Fogliano V (2005) Bread crust melanoidins as potential prebiotic ingredients. Molecular Nutrition \& Food Research 49, 673-678.

Chabance B, Jolles P, Izquierdo C, Mazoyer E, Francoual C, Drouet L, and et al. (1995) Characterization of an antithrombotic peptide from kappacasein in newborn plasma after milk ingestion. Br. J. Nutr. 73, 583-590.

Chen HM, Muramoto K, Yamauchi F, and Nokihara K (1996) Antioxidant activity of designed peptides based on the antioxidative peptide isolated from digests of a soybean protein. J. Agric. Food Chem. 44, 2619-2623.

Chen HM, Muramoto K, and Yamauchi F (1995) Structural analysis of antioxidative peptides from soybean beta-conglycinin. J. Agric. Food Chem. 43, 574-578.

Chevalier F, Chobert JM, Genot C, and Haertle T (2001) Scavenging of free radicals, antimicrobial, and cytotoxic activities of the Maillard reaction products of beta-lactoglobulin glycated with several sugars. J. Agric. Food Chem. 49, 50315038.

Comporti M (1985) Lipid peroxidation and cellular damage in toxic liver injury. Laboratory Investigation 53, 599-623.

Coughlin SR (1994) Thrombin receptor function and cardiovascular disease. Trends in Cardiovascular Med. 4, 77-83.

Migliore-Samour D, Floc'h F, and Jollès P (1989) Biologically active casein peptides implicated in immunomodulation. Journal of Dairy Research 56, 357-362.

Daniel RS, Devi KS, Augusti KT, and Sudhakaran Nair CR (2003) Mechanism of action of antiatherogenic and related effects of Ficus bengalensis Linn. flavonoids in experimental animals. Indian Journal of Experimental Biology 41, 296303.

Davalos A, Miguel M, Bartolome B, and Lopez-Fandino R (2004) Antioxidant activity of peptides derived from egg white proteins by enzymatic hydrolysis. J. Food Prot. 67, 19391944.

del Castillo MD, Ferrigno A, Acampa I, Borrelli RC, Olano A, Martínez-Rodríguez A, and Fogliano V (2007) In vitro release of angiotensin-converting enzyme inhibitors, peroxylradical scavengers and antibacterial compounds by enzymatic hydrolysis of glycated gluten. Journal of Cereal Science 45, 327-334.

Delgado-Andrade C and Morales FJ (2005) Unraveling the contribution of melanoidins to the antioxidant activity of coffee brews. J. Agric. and Food Chem. 53, 1403-1407.

Delgado-Andrade C, Rufian-Henares JA, and Morales FJ (2005) Assessing the antioxidant activity of melanoidins from coffee brews by different antioxidant methods. J. Agric. Food Chem. 53, $7832-7836$.

Drouet L, Bal dit Sollier C, Cisse M, Pignaud G, Mazoyer E, Fiat AM, and et al. (1990) The antithrombotic effect of KRDS, a lactotransferrin peptide, compared with RGDS. Nouv. Rev. Fr. Hematol. 32, 59-62.

Duangjai A, Ingkaninan K, Praputbut S, and Limpeanchob N (2013) Black pepper and piperine reduce cholesterol uptake and enhance translocation of cholesterol transporter proteins. Journal of Natural Medicines 67, 303-310.

Fox, P (2003) Milk proteins; general and historical behaviour. Pages 47-48. Vol. 1. 3rd ed. P. Fox, McSweeney PLH. ed. Kluwer Academic/Plenum Publishers, New York.

Fridovich I (1989) Superoxide dismutases. An adaptation to a paramagnetic gas. Journal of Biological Chemistry 264, 7761-7764.

Gu F, Kim JM, Hayat K, Xia S, Feng B, and Zhang X (2009) Characteristics and antioxidant activity of ultrafiltrated Maillard reaction products from a casein-glucose model system. Food Chem. 117, 48-54.

Halliwell B (1994) Free radicals, antioxidants, and hyman disease: Curoisity, cause, or consequence? Lancet 344, 721724.

Halliwell B and Gutteridge JM (1990) Role of free radicals and catalytic metal ions in human disease: An overview. Methods in Enzymology 186, 1-85.

Meisel H and Bockelmann W (1999) Bioactive peptides encrypted in milk proteins: Proteolytic activation and throphofunctional properties. Antonie Van Leeuwenhoek 76, 207-215.

Hartmann R and Meisel H (2007) Food-derived peptides with biological activity: From research to food applications. Curr. Opin. Biotechnol. 18, 163-169.

Hernandez-Ledesma B, Davalos A, Bartolome B, and Amigo L (2005) Preparation of antioxidant enzymatic hydrolysates from alphalactalbumin and beta-lactoglobulin Identification of active peptides by HPLC-MS/MS. J. Agric. Food Chem. 53, 588-593.

Hori G, Wang MF, Chan YC, Komatsu T, Wong Y, Chen TH, and et al. (2001) Soy protein hydrolyzate with bound phospholipids reduces serum cholesterol levels in hypercholesterolemic adult male volunteers. Biosci. Biotechnol. Biochem. 65, 7278.

Horne DS (2006) Casein micelle structure: models and muddles. Current Opinion in Colloid \& Interface Science 11, 148-153.

Huff MW and Carroll KK (1980) Effects of dietary proteins and amino acid mixtures on plasma cholesterol levels in rabbits. J. Nutr. 110, 1676-1685.

Hwang IG, Kim HY, Woo KS, Lee J, and Jeong HS (2011) Biological activities of Maillard reaction products (MRPs) in a sugar-amino acid model system. Food Chem. 126, 221-227.

Ishikawa S, Yano Y, Arihara K, and Itoh M (2004) Egg yolk phosvitin inhibits hydroxyl radical formation from the fenton reaction. Biosci. Biotechnol. Biochem. 68, 1324-1331.

Iwami K, Sakakibara K, and Ibuki F (1986) Involvement of postdigestion 'hydrophobic' peptides in plasma cholesterol-lowering effect of dietary plant proteins. Agric. Biol. Chem. 50, 1217-1222.

Jensen RG, Ferris AM, and Lammi-Keefe CJ (1991) The composition of milk fat. Jf Dairy Sci. 74, 3228-3243.

Jolles P, Levy-Toledano S, Fiat AM, Soria C, Gillessen D, Thomaidis A, and et al. (1986) Analogy between fibrinogen and casein effect of an undecapeptide isolated from kappa-casein on platelet function. Eur. J. Biochem. 158, 379-382.

Keaney JF Jr, Gaziano JM, Xu A, and et al. (1993) Dietary antioxidants preserve endothelium-dependent vessel relaxa- 
tion in cholesterol-fed rabbits. Proc. Natl. Acad. Sci. USA 90, 11880-11884.

Keri Marshall, N (2004) Therapeutic applications of whey protein. Alternative Medicine Review 9, 136-156.

Kitts DD and Weiler K (2003) Bioactive proteins and pepti- des from food sources. Applications of bioprocesses used in isolation and recovery. Curr. Pharm. Des. 1309-1323.

Korhonen H and Pihlanto A (2003) Food-derived bioactive peptides-opportunities for designing future foods. Curr. Pharm. Des. 9, 1297-1308.

Kovacs-Nolan J, Phillips M, and Mine Y (2005) Advances in the value of eggs and egg components for human health. $J$. Agric. Food Chem. 53, 8421-8431.

Kwon YII, Vattem DA, and Shetty K (2006) Evaluation of clonal herbs of Lamiaceae species for management of diabetes and hypertension. Asia Pacific J. Clinical Nutrition 15, 107-118.

LeBlanc J, Matar C, Valdez J, LeBlanc J, and Perdigon G (2002) Immunomodulating effects of peptidic fractions issued from milk fermented with Lactobacillus helveticus. J. Dairy Sci. 85, 2733-2742.

Mackman N (2008) Triggers, targets and treatments for thrombosis. Nature 451, 914-918.

Maeno M, Yamamoto N, and Takano T (1996) Identification of an antihypertensive peptide from casein hydrolysate produced by a proteinase from Lactobacillus helveticus CP790. J. Dairy Sci. 79, 1316-1321.

Making S, Nakashima H, Minami K, Moriyama R, Takao S (1988) Bile acid-binding protein from soybean seed: Isolation, partial characterization and insulin-stimulating activity. Agric. Biol. Chem. 52, 803-809.

Manzocco L, Calligaris S, Mastrocola D, Nicoli MC, and Le- rici CR (2000) Review of non-enzymatic browning and antioxidant capacity in processed foods. Trends in Food Science \& Technology 11, 340-346.

Maubois JL, Leonil J, Trouve R, and Bouhallab S (1991) Milk peptides with physiological activities: III Peptides with a cardiovascular effect: antithrombotic and antihypertensive activity. Lait. 71, 249-255.

Mauron J (1981) The Maillard reaction in food; a critical review from the nutritional standpoint. Progress in Food \& Nutrition Science 5, 5.

Meisel H (1997) Biochemical properties of regulatory pepti- des derived from milk proteins. Biopolymers 43, 119-128.

Meisel H (2004) Multifunctional peptides encrypted in milk proteins. Biofactors 21, 55-61.

Meisel H and FitzGerald RJ (2003) Biofunctional peptides from milk proteins: mineral binding and cytomodulatory ef- fects. Curr. Pharm. Des. 9, 1289-1295.

Meisel H (2005) Biochemical properties of peptides encryp- ted in bovine milk proteins. Curr. Med. Chem. 12, 1905-1919.

Morales FJ (2005) Assessing the non-specific hydroxyl radical scavenging properties of melanoidins in a Fenton-type reaction system. Analytica Chimica Acta 534, 171-176.

Nagaoka S, FutamuraY, Miwa K, AwanoT, Yamauchi K, KanamaruY, and et al. (2001) Identification of novel hypocholesterolemic peptides derived from bovine milk beta-lactoglobulin. Biochem. Biophys. Res. Commun. 281, 11-17.
Nagaoka S, Kanamaru Y, Kojima T, and Kuwata T (1992) Comparative studies on the serum cholesterol lowering action of whey protein and soybean protein in rats. Biosci. Biotechnol. Biochem. 56, 1484-1485.

Nagaoka S (1996) Studies on regulation of cholesterol metabolism induced by dietary food constituents or xenobiotics. J. Jpn. Soc. Nutr. Food Sci. 49, 303-313.

Nagaoka S, Kanamaru Y, and Kuzuya Y (1991) Effect of whey protein and casein on the plasma and liver lipid in rats. Agric. Biol. Chem. 55, 813-818.

Nagata Y, Ishiwaki N, and Sugano M (1982) Studies on the mechanism of antihypercholesterolemic action of soy protein and soy proteintype amino acid mixtures in relation to the casein counterparts in rats. $J$. Nutr. 112, 1614-1625.

Ngamukote S, Makynen K, Thilawech T, and Adisakwattana S (2011) Cholesterol-lowering activity of the major polyphenols in grape seed. Molecules 16, 5054-5061.

Oh NS, Kwon HS, Lee HA, Joung JY, Lee JY, Shin YK, Baick SC, Park MR, Kim Y, Lee KW, and Kim SH (2014) Preventive effect of fermented Maillard reaction products from milk proteins in cardiovascular health. J. Dairy Sci. 97, 33003313.

Oh NS, Park MR, Lee KW, Kim SH, and Kim Y (2015) Die- tary Maillard reaction products and their fermented products reduce cardiovascular risk in an animal model. J. Dairy Sci. doi.org/10.3168/jds.2015-9308.

Ohara Y, Peterson TE, and Harrison DG (1993) Hypercholesterolemia increases endothelial superoxide anion production. $J$. Clin. Invest. 91, 2546-2551.

Pak VV, Koo MS, Kasymova TD, and Kwon DY (2005) Isolation and identification of peptides from soy 11S-globulin with hypocholesterolemic activity. Chem. Nat. Compd. 41, 710714.

Pehrsson P, Haytowitz D, Holden J, Perry C, and Beckler D (2000) USDA's national food and nutrient analysis program: Food sampling. Journal of Food Composition and Analysis 13, 379-389.

Pfeuffer M and Schrezenmeir J (2000) Bioactive substances in milk with properties decreasing risk of cardiovascular diseases. Br. J. Nutr. 84(Suppl 1), S155-S159.

Sato R, Noguchi T, and Naito H (1986) Casein phosphopeptide (CPP) enhances calcium absorption from the ligated segment of rat small intestine. Journal of Nutritional Science and Vitaminology 32, 67-76.

Rival SG, Fornaroli S, Boeriu CG, and Wichers HJ (2001) Caseins and casein hydrolysates: 1 Lipoxygenase inhibitory properties. J. Agric. Food Chem. 49, 287-294.

Rufian-Henares JA and Morales FJ (2007) Functional properties of melanoidins: In vitro antioxidant, antimicrobial and antihypertensive activities. Food Res. Int. 40, 995-1002.

Severin S and Wenshui X (2005) Milk biologically active components as nutraceuticals: Review. Crit. Rev. Food Sci. Nutr. 45, 645-656.

Steinbrecher UP, Zhang H, and Lougheed M (1990) Role of oxidatively modified LDL in atherosclerosis. Free Radical Biolology and Medicine 9, 155-168.

Suetsuna K, Ukeda H, and Ochi H (2000) Isolation and character- 
ization of free radical scavenging activities peptides derived from casein. J. Nutr. Biochem. 11, 128-131.

Sugano M, Goto S, Yamada Y, Yoshida K, Hashimoto Y, Matsuo T, and et al. (1990) Cholesterol-lowering activity of various undigested fractions of soybean protein in rats. J. Nutr. 120, 977-985.

Takenaka Y, Utsumi S, and Yoshikawa M (2000) Introduction of enterostatin (VPDPR) and a related sequence into soy- bean proglycinin $\mathrm{A} 1 \mathrm{aB} 1 \mathrm{~b}$ subunit by site-directed mutagenesis. Biosci. Biotechnol. Biochem. 64, 2731-2733.

Tomita M, Takase M, Bellamy W, and Shimamura S (1994) A review: The active peptide of lactoferrin. Acta Paediatrica Japonica; Overseas edition 36, 585-591.

Turner LG, Swaisgood HE, and Hansen AP (1978) Interaction of lactose and proteins of skim milk during ultra-high-temperature processing 1, 2. J. Dairy Sci. 61, 384-392.

Van Boekel M (1998) Effect of heating on Maillard reactions in milk. Food Chem. 62, 403-414.

Walstra P and Jenness R (1984) Dairy chemistry \& physics. John Wiley \& Sons.
Wang MF, Yamamoto S, Chung HM, Chung SY, Miyatani S, Mori M, and et al. (1995) Antihypercholesterolemic effect of undigested fraction of soybean protein in young female volunteers. J. Nutr. Sci. Vitaminol (Tokyo) 41, 187-195.

Weitz JI and Crowther M (2002) Direct thrombin inhibitors. Thrombosis Research 106, V275-V284.

Wergedahl H, Liaset B, Gudbrandsen OA, Lied E, Espe M, Muna $\mathrm{Z}$, and et al. (2004) Fish protein hydrolysate reduces plasma total cholesterol, increases the proportion of HDL cholesterol, and lowers acyl-CoA: cholesterol acyltransferase activity in liver of Zucker rats. J. Nutr. 134, 1320-1327.

Yamamoto N, Akino A, and Takano T (1994) Antihypertensive effect of the peptides derived from casein by an extracellular proteinase from Lactobacillus helveticus CP790. J. Dairy Sci. 77, 917-922.

Yu BP (1994) Cellular defenses against damage from reactive oxygen species. Physiological Reviews 74, 139-162.

Zhang X and Beynen AC (1993) Lowering effect of dietary milkwhey protein $\mathrm{v}$ casein on plasma and liver cholesterol concentrations in rats. Br. J. Nutr. 70, 139-146. 